Research Paper

\title{
Tube-Like Structures with Co-Expression of D2-40 and CD34: Newly Formed Vasculatures?
}

\author{
Bin Jiang ${ }^{1 凶}$, Jeffrey Mason ${ }^{2}$, Anahid Jewett ${ }^{3}$, William CS Cho 4 , Yan-gao Man ${ }^{5}$
}

1. National Medical Centre of Colorectal Disease, The Third Affiliated Hospital, Nanjing University of Traditional Chinese Medicine (TCM), Nanjing, China.

2. Veterans Affair Medical Center, Washington, DC, USA.

3. Tumor Immunology Laboratory, Division of Oral Biology and Medicine, Jonsson Comprehensive Cancer Center, UCLA School of Dentistry, Los Angeles, CA. USA.

4. Department of Clinical Oncology, Queen Elizabeth Hospital, Hong Kong, China.

5. Diagnostic and Translational Research Center, Henry Jackson Foundation, MD, USA and College of Animal Science and Veterinary Medicine, Jilin University, Changchun, Jilin, China.

Corresponding author: Bin Jiang, MD, PhD. Associate Director, National Medical Centre of Colorectal Diseases Associate professor, University of Traditional Chinese Medicine, The Third Affiliated Hospital, Nanjing University of Traditional Chinese Medicine, Nanjing, China. Phone: 18951755051; E-mail: jbfirsth@yahoo.com.cn; or jbfirsth1@gmail.com.

(C) Ivyspring International Publisher. This is an open-access article distributed under the terms of the Creative Commons License (http://creativecommons.org/ licenses/by-nc-nd/3.0/). Reproduction is permitted for personal, noncommercial use, provided that the article is in whole, unmodified, and properly cited.

Received: 2012.09.01; Accepted: 2012.09.28; Published: 2012.10.19

\begin{abstract}
Background: A great number of in vitro and in vivo studies have suggested that many pathways or factors can stimulate angiogenesis and lymphangiogenesis, which facilitate tumor progression and metastasis. However, the morphological and immunohistochemical profile of newly formed vasculatures has not been elucidated, making it difficult to differentiate them from the pre-existing ones, and to identify their unique molecular profiles for diagnosis and therapeutic interventions.

Experimental findings: As cytokeratin (CK)-19 is a well-recognized stem cell marker and CK-19-positive cells are frequently detected in the peripheral blood of patients with metastatic cancer, our recent studies have assessed the involvement of CK-19 in the formation of new vasculatures in primary colorectal cancer (CRC) tissues. Our studies showed that a subset of lymph node-positive cases harbored some isolated normal epithelial structures with distinct CK-19 immunostaining within an otherwise CK-19-negative background. These structures are exclusively located within or adjacent to lymphoid follicles and are often surrounded by tube-like structures expressing lymphatic endothelial marker D2-40. Similar structures are more frequently seen at the junctions between pre-invasive and invasive CRC with the following features: (I). they consist of a single layer of endothelial cells that express both D2-40 and CD34, (2). their endothelial walls are often incomplete with disseminated cells protruding into the adjacent stroma, and (3). they are exclusively associated with disseminated CK-I9-positive cells

Hypothesis: Based on these findings, we propose that these tube-like structures represent newly formed vasculatures, which are derived by the convergence of aberrant lymphocyte infiltration and tumor stem cells. Because of their close physical proximity, tumor stem cells within the epithelial and stromal components contribute equally and coordinately to the morphogenesis of new vasculatures, which constitutes the basis for the unique morphologic and immunohistochemical features of newly formed vasculatures. Our hypothesis appears to be applicable to all epithelium-derived cancers.
\end{abstract}

Key words: CK-19, epithelium-derived cancers, tube-like structures 


\section{Introduction}

Colorectal cancer (CRC) is one of the most common human malignancies worldwide, and it is estimated that about 1,200,000 people are diagnosed with, and over 600,000 people die from, CRC annually [1]. Unfortunately, both the incidence and mortality of CRC in the developing countries, including China, have risen linearly during the past 10-years [2-3]. Based on the geographic trends, the world annual incidence of CRC could exceed more than 2.2 million cases within the next 20-years [1]. Colorectal carcinogenesis is believed to be a multi-stage process originating from a localized adenoma that linearly progresses to an intra-mucosal carcinoma, to an invasive lesion, and to metastatic cancer [4-6]. Over $90 \%$ of CRC-related mortality results from cancer metastasis. The five-year survival rate is greater than $75 \%$ for patients with non-metastatic disease, but is about $10 \%$ in patients with metastatic CRC [7-9]. Consequently, the early detection of CRC patients at risk to develop metastatic disease for early aggressive interventions could lead to improved prognosis and reduce treatment-related costs.

CRC metastasis is believed to be a multi-stage process, progressing sequentially from initial dissociation from the primary site, to intravasation, to circulation, to extravasation, to migration, and to colonization in new sites [10-12]. As tumor cell dissociation and intravasation are absolutely required for the initiation of the metastatic cascade, great efforts have been made to identify the underlying mechanism associated with these events. It has been suggested that cancer cells not only can intravasate into pre-existing vasculatures, but also can actively induce the formation of new vasculatures [13]. A number of factors, including vascular endothelial growth factor-C (VEGF-C) and VEGF-D, hepatocyte growth factor, angiopoietin-1, platelet derived growth factor-BB, insulin-like growth factors 1 and 2, fibroblast growth factor-2, chronic inflammation, podoplanin, and macrophages, have been reported to promote endothelial cell proliferation, angiogenesis, migration, and survival via a number of pathways [13-37]. These pathways include the VEGF-A/VEGFR-2, extracellular signal-regulated kinase $1 / 2$, phosphatidylinositol 3-kinase/AKT, and the c-Jun $\mathrm{NH}_{2}$-terminal kinase $1 / 2$ pathways [13-37].

None of these studies, however, has provided comparative morphological or immunohistochemical data that differentiate the newly formed vasculatures from pre-existing ones. Consequently, the molecular and biochemical profile of newly formed vasculatures is unknown, making it difficult, if not impossible, to identify and isolate unique molecules expressed in these structures for clinical applications. More importantly, the epithelium, which is the histological origin of cancer, is normally devoid of lymphatic ducts and blood vessels. In addition, all normal and pre-invasive cancer cells are conjoined by intercellular junctions and surface adhesion molecules and are also physically separated from vascular structures by a dense tumor capsule (the basement membrane). Therefore, invasion and metastasis initiating cells have to cross the capsule wall and escape into the stroma as individual cells or small cell clusters in order to intravasate pre-existing vasculatures or to induce the formation of new vasculatures. The detailed mechanisms of these events, however, have not been elucidated in human tissues.

Based on studies of human breast and prostate cancer, we have proposed a novel hypothesis that tumor invasion and metastasis result from the convergence of an injury to the epithelial capsule, the immune response to the injury, and the presence of tumor stem cells within the capsules at the site of injuries [38-50]. As epithelial cells are normally contained within capsules, focal degeneration of the capsule due to age or disease attracts lymphocyte infiltration, which degrades the degenerating capsule resulting in the formation of a focal disruption. If epithelial cells overlying the disruption are terminally differentiated, no or minimal proliferation will occur and the capsule will be repaired. If the disruption occurs in the capsule underlying undifferentiated progenitor or tumor stem cells, however, these cells are afforded the opportunity to proliferate leading to their "budding" from the disruption and subsequent growth into the stroma [38-50]. Once proliferating cell buds are formed, their interaction with infiltrated lymphocytes gives rise to an early pathway for metastasis. Specifically, as lymphocytes infiltrate tumor buds, they disrupt the intercellular junctions and surface adhesion molecules causing the dissociation of some cells from the bud. During this process, tumor cells and lymphocytes can form stable pairings as tumor-lymphocyte chimeras (TLCs). This perilous coupling allows tumor stem cells to avail themselves of the lymphocyte's natural ability to migrate, to breach cell barriers, and to intravasate into vascular structures. Theses facilitate their travel to distant organs where the pair can extravasate, providing the potential seed of a metastatic lesion. Our hypothesis has been recognized as more compatible with existing experimental evidence than the traditional "protoelytic enzyme" theory [51].

As only stem cells retain the potential for unlimited proliferation and multi-lineage differentiation 
in the adult organs, and that tumor-infiltrating immune cells are major factors to stimulate angiogenesis and lymphangiogenesis, we have speculated that the formation of new vasculatures is mediated by the convergence of stem cells budding and lymphocyte infiltration. To validate our speculation, we have compared the pattern and frequency of cell budding and vascular structures between age- and type-matched CRC with $(N=37)$ and without $(N=55)$ positive lymph nodes. These cases were retrieved under an IRB-approved protocol (\#2008001) from the Nanjing Municipal Hospital of Nanjing University of Traditional Chinese Medicine (TCM), China. The main clinical parameters of patients and tumors were listed in Table 1. The reasons to select CRC as the study target are three-fold: (1) the colonic tissues share a similar structural profile with other epithelial tissues [52], (2) colorectal carcinogenesis is believed to share the same mechanism and progression process with other cancers [4-6], and (3) colon tissues harbor the highest concentration of immune cells, but have the highest rate of metastasis [53-57].

Table I. Main clinical features of samples used in the study.

\begin{tabular}{llll}
\hline Clinical Parameters & Node negative & Node positive & $p$ \\
\hline Tumor type & Adenocarcinoma & Adenocarcinoma & N/A \\
$\begin{array}{l}\text { Tumor size } \\
\text { Mean age (years) }\end{array}$ & $4.55 \times 3.54 \mathrm{CM}$ & $4.95 \times 3.68 \mathrm{CM}$ & $>0.05$ \\
$\begin{array}{l}\text { Depth of invasion } \\
\begin{array}{l}\text { Submucosa or superfi- } \\
\text { cial MP }\end{array}\end{array}$ & $7(12.7 \%)$ & $4(10.8 \%)$ & $>0.05$ \\
$\begin{array}{l}\text { Deep MP and subse- } \\
\text { rosa }\end{array}$ & $48(87.2 \%)$ & $33(89.2 \%)$ & \\
\hline
\end{tabular}

\section{Novel findings and hypothesis}

As CK-19 is a well-recognized stem cell marker and CK-19-positive cells are very frequently detected in the peripheral blood of patients with metastatic cancer [58-63], our studies have assessed the involvement of CK-19 in the formation of new vasculatures. Using double immunohistochemistry, our studies showed that a subset of lymph node-positive cases harbored isolated normal epithelial structures with distinct CK-19 immunostaining within an otherwise CK-19-negative background. As shown in Figure 1, these structures are exclusively located within or adjacent to lymphoid follicles with marked alterations in cell density, size, shape, and nuclear structures, and with significantly increased lymphatic duct density, compared to their adjacent CK-19-negative counterparts.
These CK-19-positive epithelial structures were often physically associated with elongated cells that exhibit distinct D2-40 immunostaining. These elongated cells were predominantly associated with isolated CK-19-positive structures within, or adjacent to, lymphoid follicles, and frequently formed a single layered tube-like structure partially or completely surrounding these structures (Fig 2).

In some cases, these elongated cells appear to be physically conjoined with CK-19-positive cells. As shown in Figure 3, the plasma membranes of these two cell types appear to be fused, or the elongated cells appear to be the direct physical extension of the CK-19-positive epithelial cells.

Some isolated CK-19-positive cell clusters budding from normal epithelial structures are physically located within the tube-like structures. These tube-like structures have the following features:

- they consist of a single layer of endothelial cells that express both D2-40 and CD34 (Fig 4).

- Their wall is often incomplete with disseminated cells protruding into the adjacent stroma.

As shown in Figure 5, the wall of these structures is often incomplete, and disseminated cells are physically connected with surrounding cells through the gaps within these tube-like structures.

- They are exclusively associated with disseminated CK-19-positive cells

As shown in Figure 6, all tube-like structures with CK-19-positive cells co-express D2-40 and CD34, but an adjacent vein without disseminated cells are negative for D2-40 and only express CD34.

Together, our findings suggest that these tube-like structures are newly formed vasculatures derived from the following pathways depicted in Figure 7, which is a composite taken from figures 2 and 3:

- Focal tumor capsule degeneration due to age or disease attracts lymphocyte infiltration that degrades these regions resulting in the formation of focal disruptions in the capsule. These gaps selectively favor monoclonal proliferation of the overlying tumor stem cells or progenitors if they are present

- Tumor stem cells or progenitors preferentially express high levels of cytokeratin 19, leading to the loss or reduction of the tumor capsule formation, and increased proliferation and mobility [64-65].

- Lymphocytes infiltrate the proliferating buds and disrupt intercellular junctions and surface adhesion molecules causing the dissociation of some cells from the buds and migration into the 
stroma.

- Within the stroma, different growth factors, including vascular endothelial growth factor and epidermal growth factor, stimulate proliferation of budding tumor stem cells leading to the formation of an endothelial cell lineage in responding to CK-19 expression-induced alterations [66-68].

- Lymphocyte infiltration also stimulates prolifer- ation of the surrounding fibroblasts that harbor mesenchymal stem cells leading to the formation of an endothelial cell lineage [69].

- Due to their close physical proximity, stem cells within both the epithelial and stromal components equally contribute to newly formed vasculatures leading to the co-expression of D2-40 and CD34.
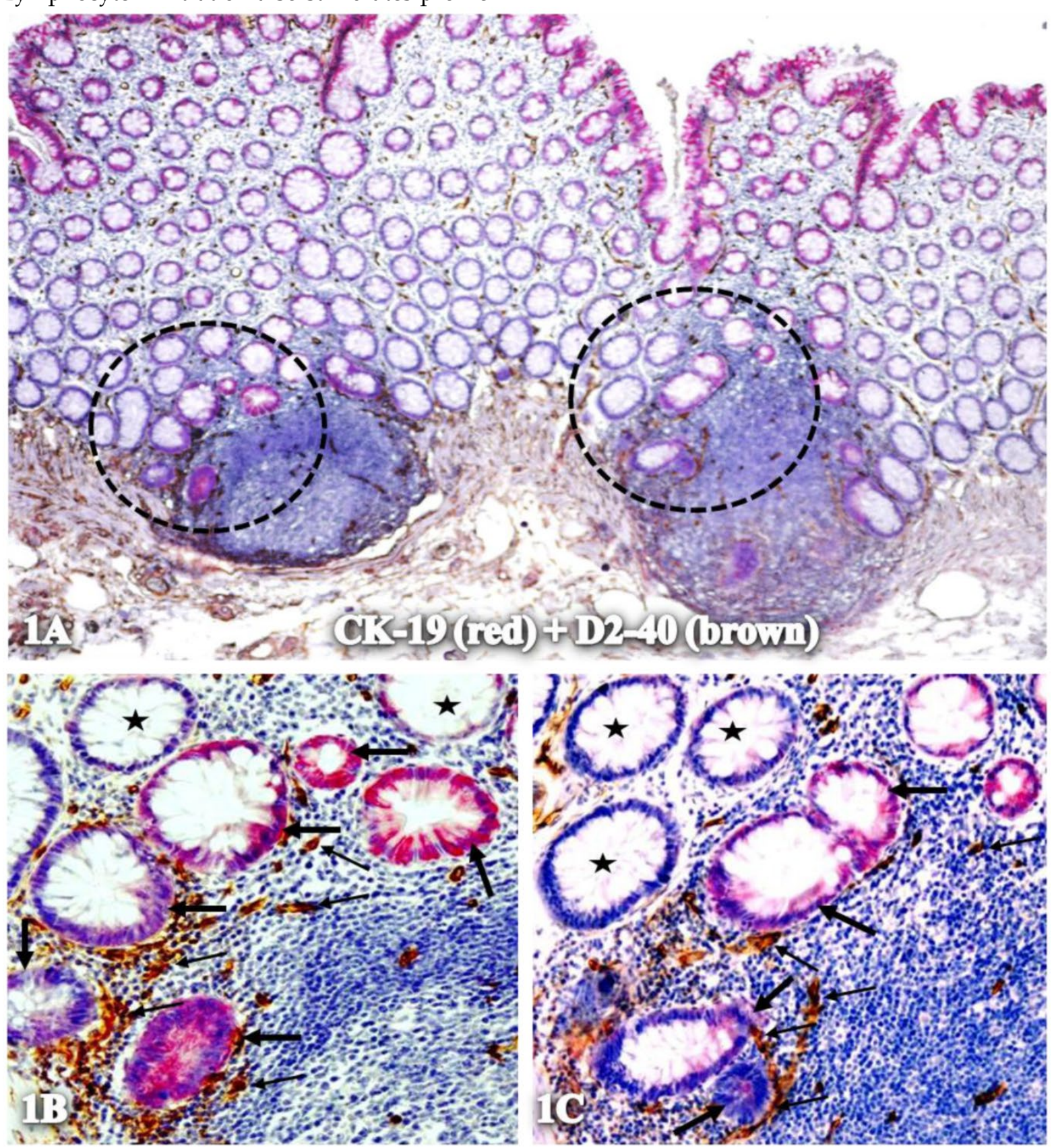

Figure I. Isolated CK-I9-positive epithelial structures with increased lymphatic duct density within lymphoid follicles. A normal colonic section adjacent to tumors was double immunostained for CK-19 (red) and D2-40 (brown). Circles in A identify low magnification views of structures in B and C. Thick and thin arrows identify CK-19-positive structures and lymphatic ducts, respectively. Stars identify normal epithelial structures without CK-19 expression. A: 80X. B and C: 400X 


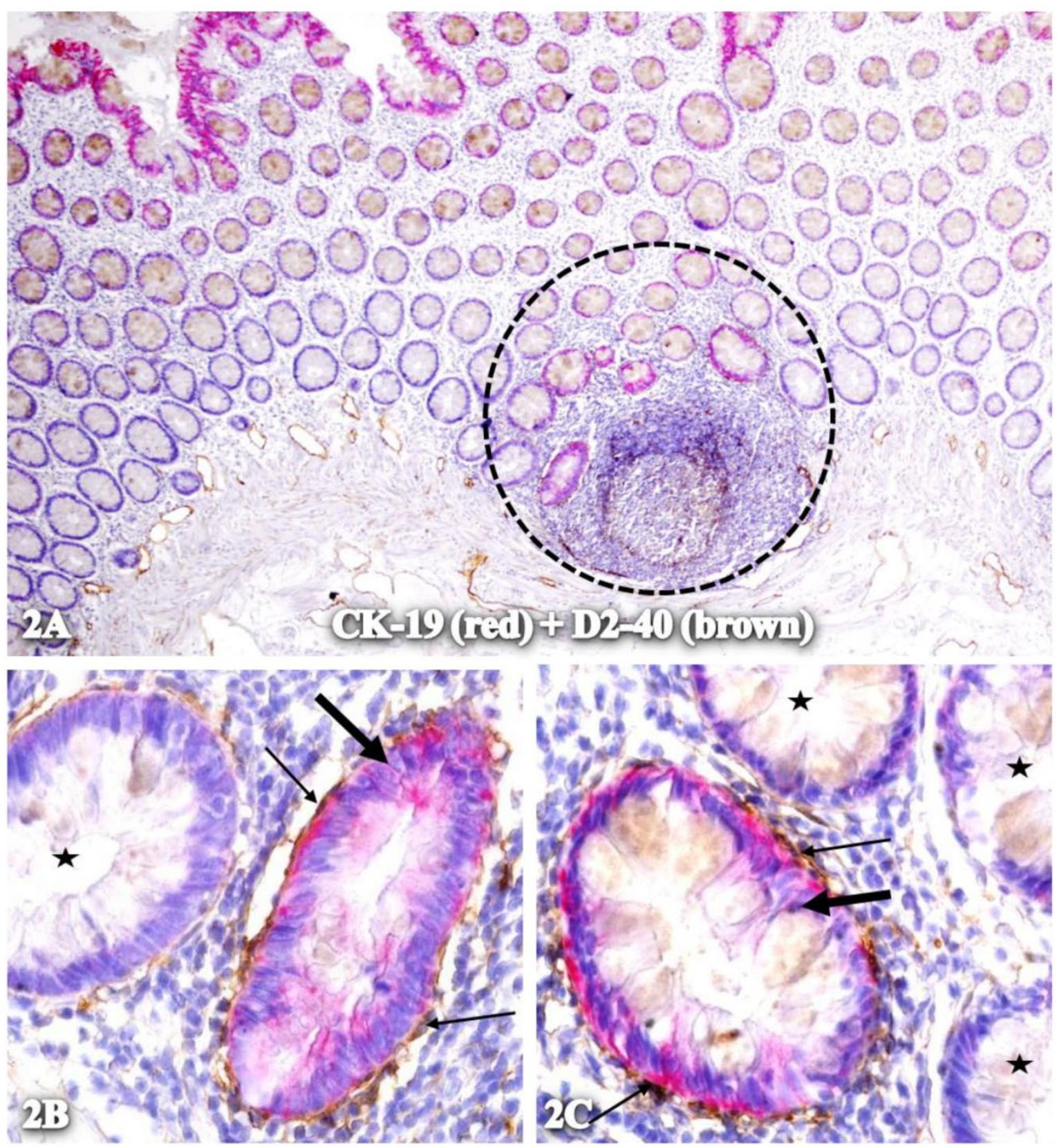

Figure 2. Physical association of CK-19-positive structures containing elongated cells with D2-40 expression. A normal colonic section adjacent to tumors was double immunostained for CK-19 (red) and D2-40 (brown). The circle in A identifies the low magnification view of the structures in B and C. Starts identify normal epithelial structures. Thick and thin arrows identify CK-19-positive structures and surrounding D2-40-positive cells, respectively. A: 80X. B and C: 400X. 

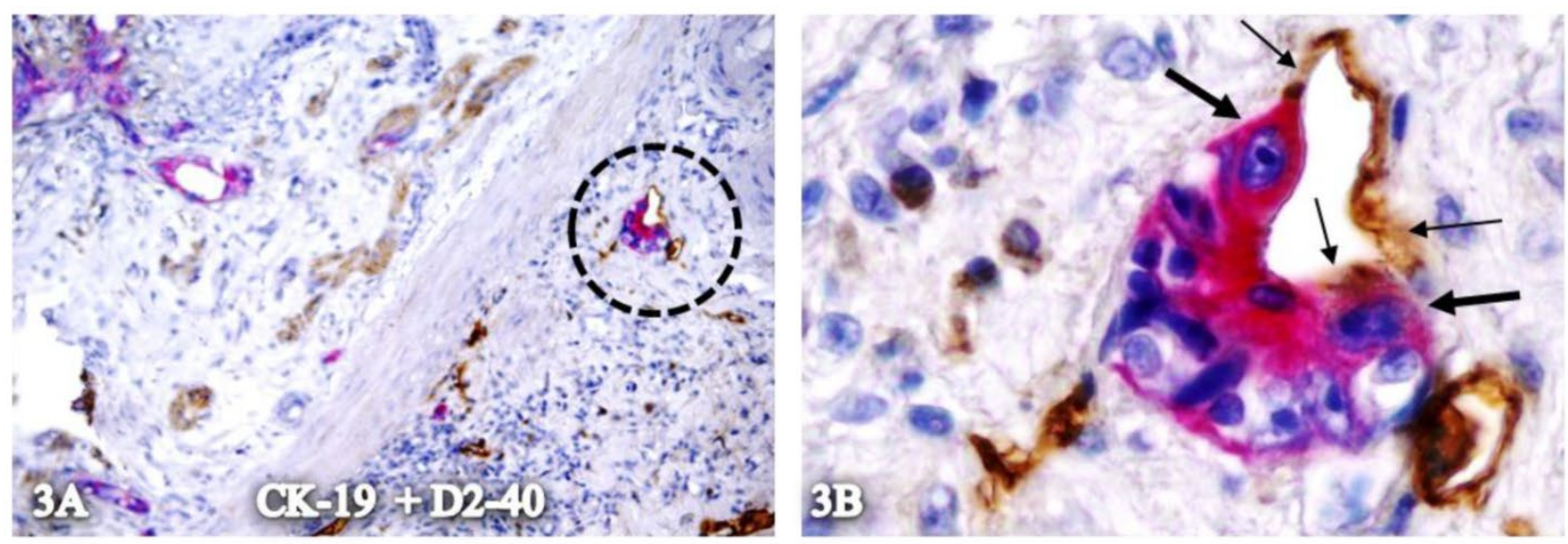

Figure 3: Plasma membrane conjunction of CK-19-positive cells and elongated cells with D2-40 expression. A CRC section was double immunostained for CK-19 (red) and D2-40 (brown). The circle in A identifies the low magnification view of the structure in B. Thick and thin arrows identify CK-19- and D2-40-positive cells, respectively. A: 80X. B: 400X.
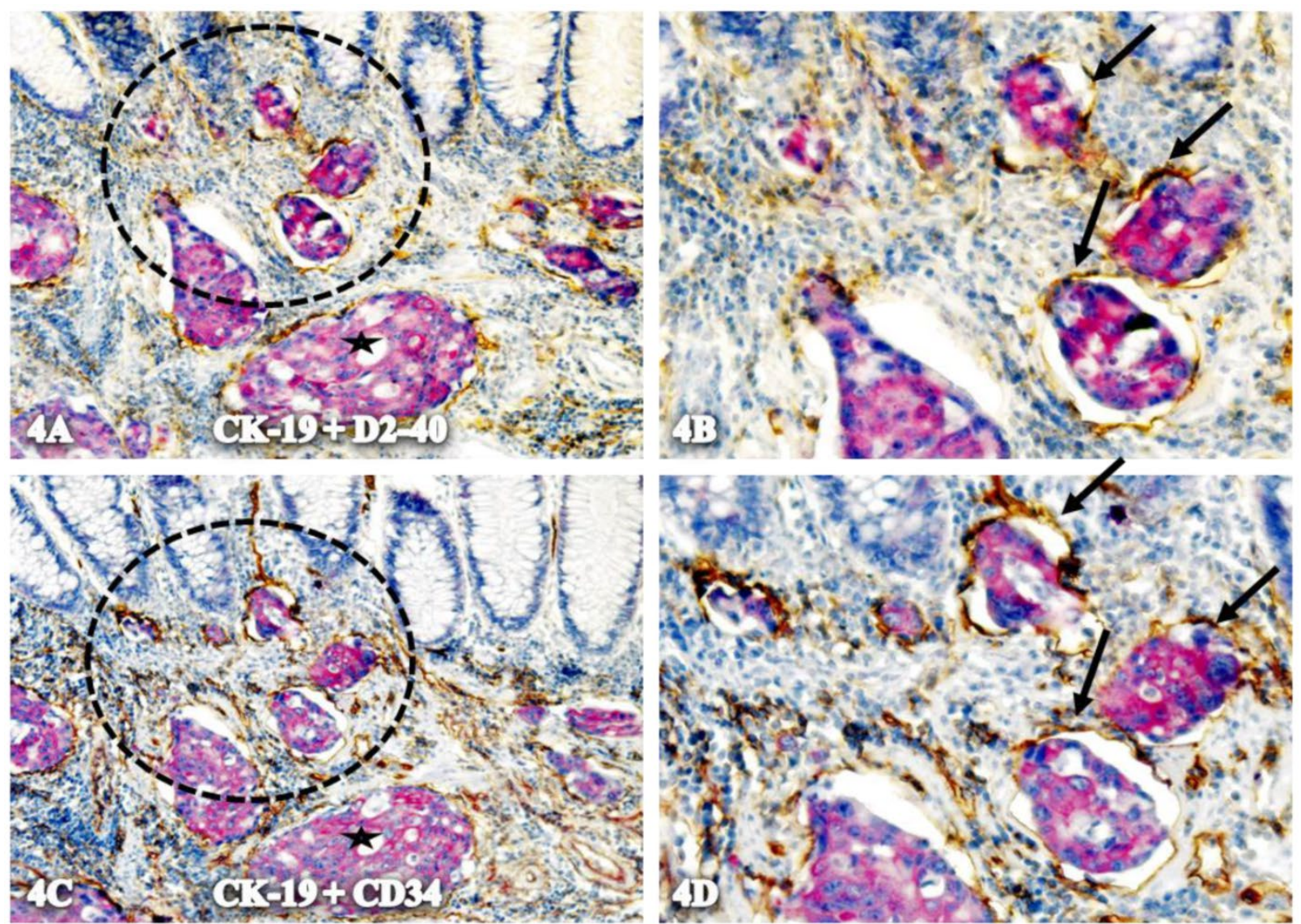

Figure 4. Localization of CK-19-positive cells within tube-like structures co-expressing D2-40 and CD34. A set of two adjacent sections from a node-positive case was double-immunostained for CK-19 (red) plus D2-40 or CD 34 (brown). Circles in A and $C$ identify low magnification views of the structures in B and D. Arrows identify tube-like structures with both D2-40 and CD34 immunostaining. Stars identify invasive cancer. A \& C: I50. B \& D: 400X. 

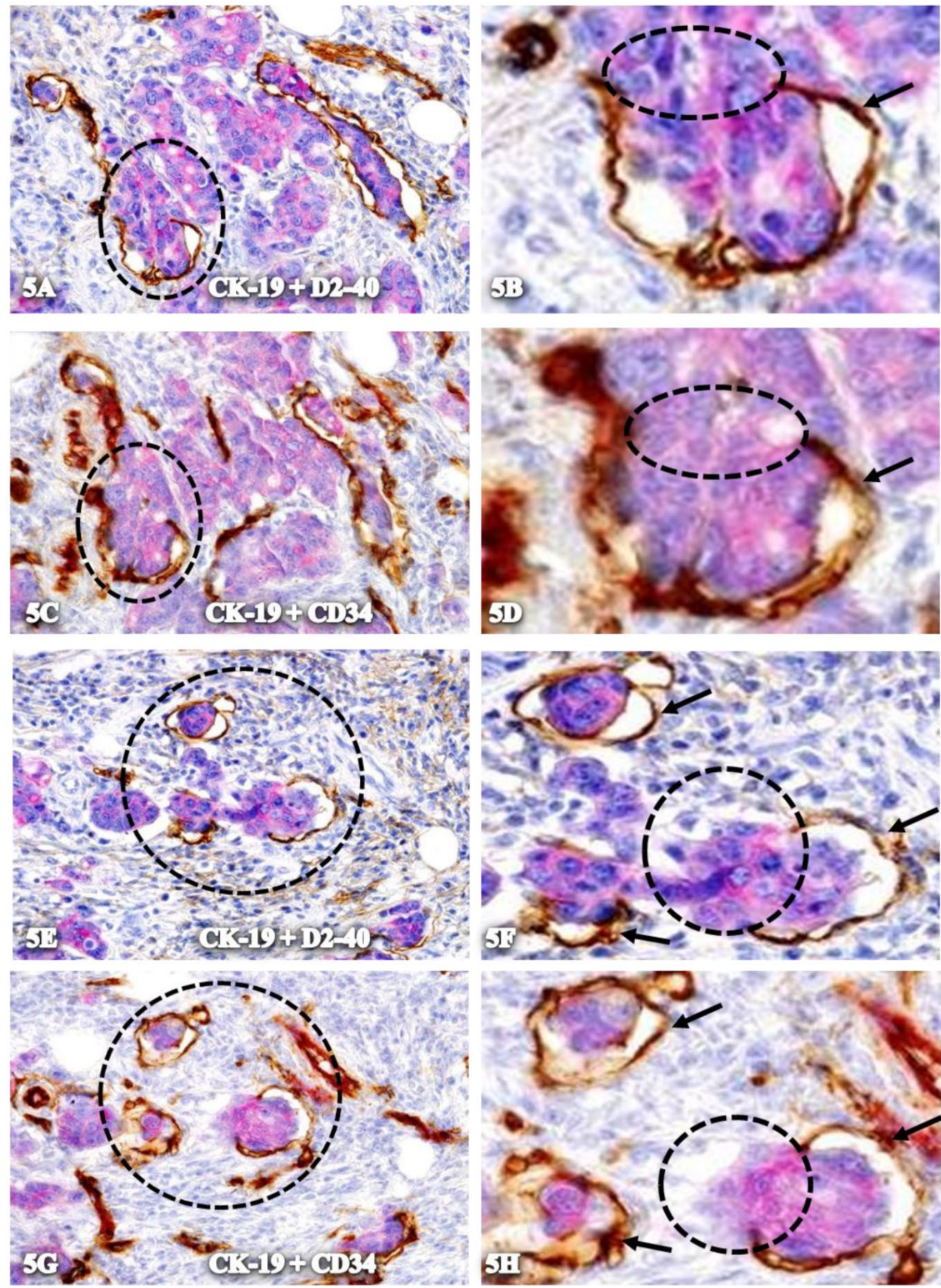

Figure 5. Physical connection of disseminated cells with adjacent cells through gaps within tube-like structures. Two sets of adjacent CRC sections from a node-positive case were double immunostained for CK-19 (red) plus D2-40 or CD34 (brown). Black circles identify low magnification reviews of structures in $B$ and $D$. Yellow circles identify the physical gaps within the tube-like structures. Arrows identify the wall of the structures. A,C,E, and G: I50X. B,D,F, and H: 400X. 

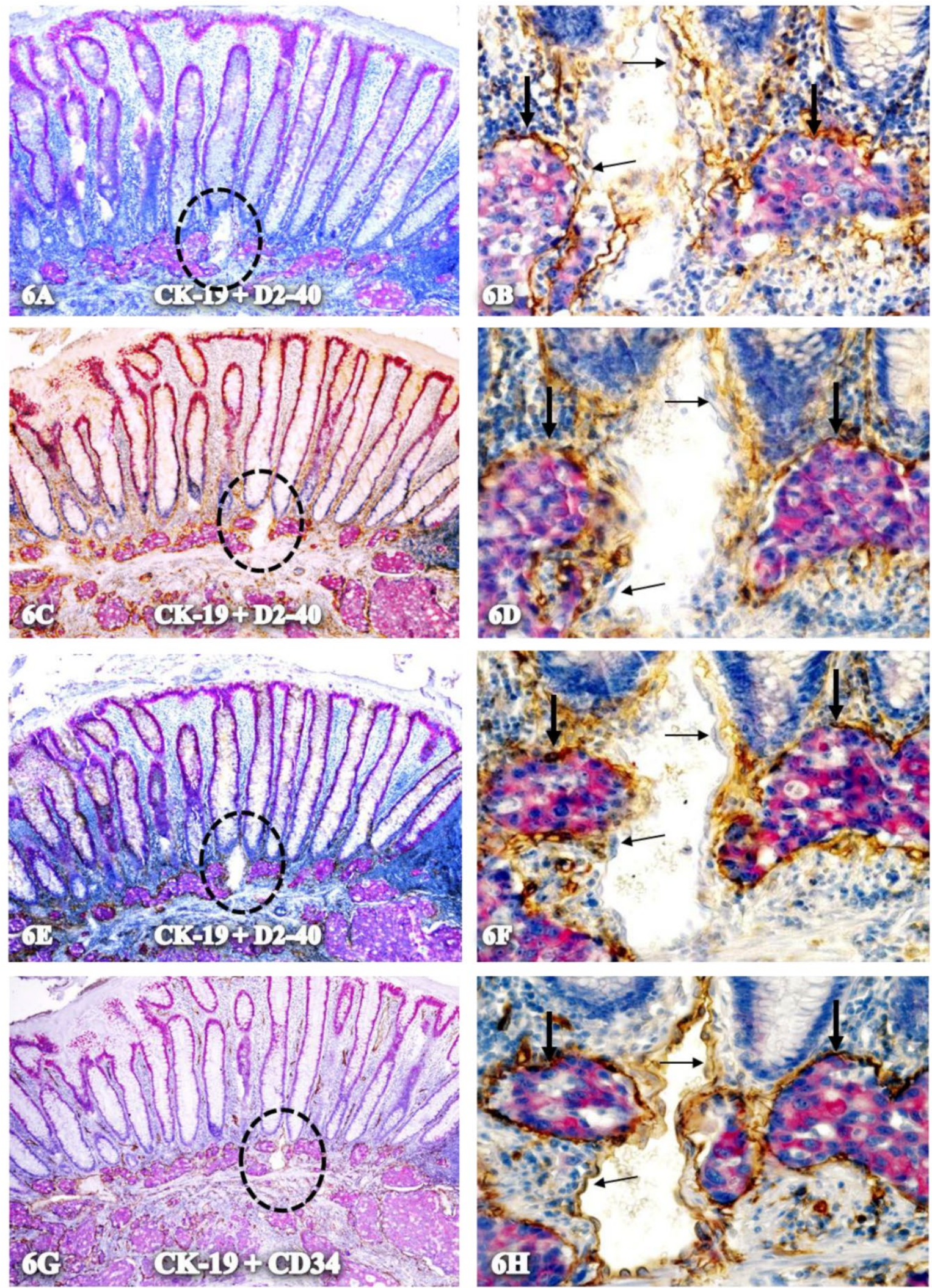

Figure 6. Exclusive association with disseminated cells. $A$ set of four adjacent $C R C$ sections were double-immunostained for CK-19 (red) plus D2-40 (A-F) or CD34 (G-H) (brown). Circles identify low magnification views of structures in B, D, F, and $\mathrm{H}$. Thick arrows identify tube-like structures co-expressing D2-40 and CD34. Thin arrows identify endothelial cells that express only CD34. A,C,E, and $G$. 100X. B, D, F, and $\mathrm{H}$ : a higher magnification (400X) of $A, C, E$, and $G$, respectively. 


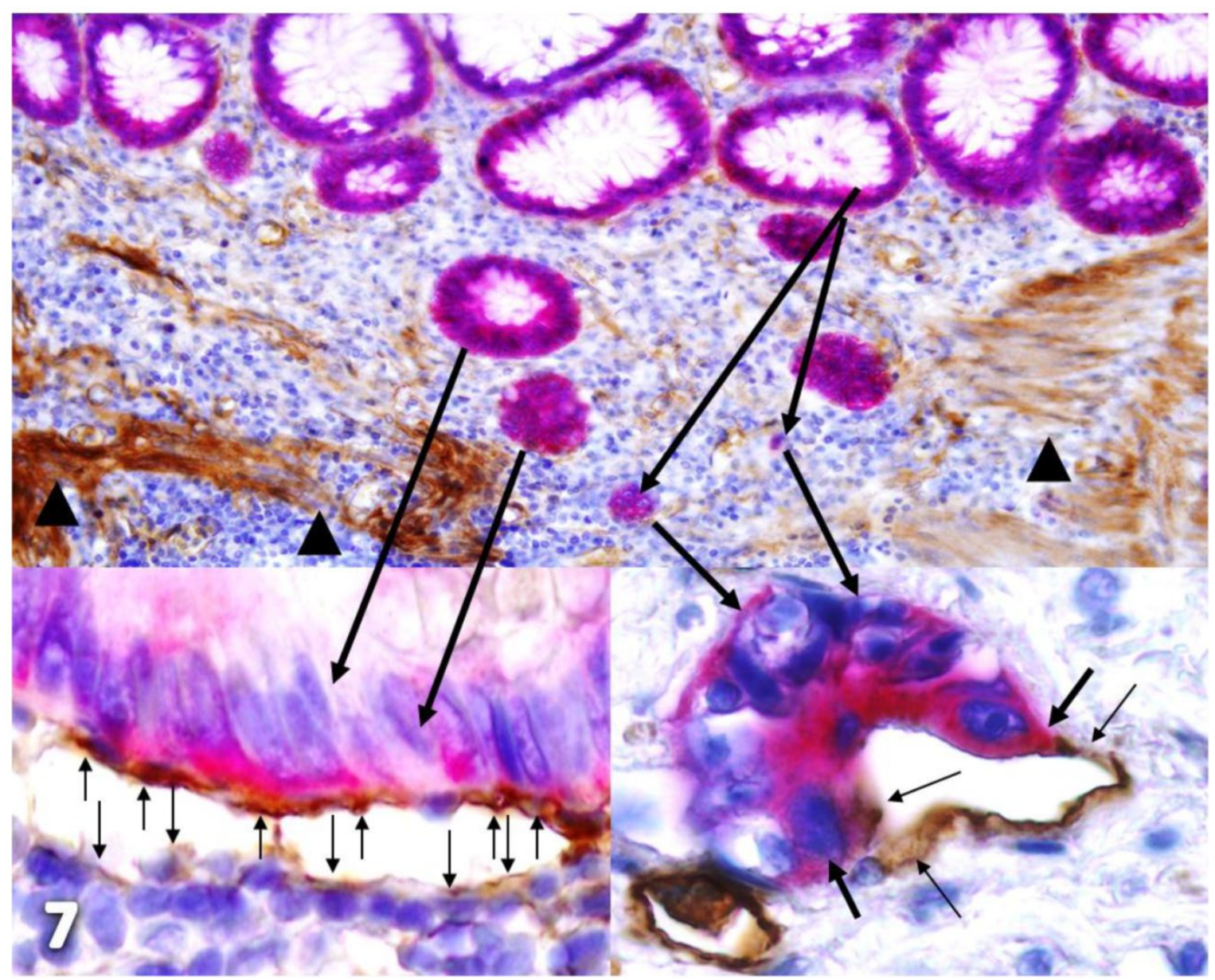

Figure 7. Hypothesized pathways of new vasculature formation. Normal colonic sections adjacent to tumors were double-immunostained for CK-19 (red) and collagen IV or D2-40 (brown). Stars identify normal epithelial structures. Thick black arrows identify dissociated cells or cell clusters. Thin arrows identify D2-40 positive cells. Arrowheads identify the MM. The circle identifies a gap in MM. Note that some tumor cells (green arrows) are physically conjoined with D2-40-positive cells.

\section{Implications of our findings and hypothe- sis}

To the best of our knowledge, this is the first report to describe the hypothesized morphological and immunohistochemical features of newly formed vasculatures based on our novel findings from human clinical tumor samples. It is not known why such or similar findings have not been previously reported. It is our speculation that the most likely reason might be that these alterations, especially the co-expression of D2-40 and CD34, can be seen only in double immunostained tissue sections, whereas double immunohistochemistry is barely used in the clinical laboratories. These novel findings have led us to propose that newly formed vasculatures are derived from the convergence of lymphocyte infiltration and stem cells in both the epithelial and stromal components. Due to their close physical proximity, stem cells within the epithelium and stroma equally and coor- dinately contribute to the formation of new vasculatures, which provides the basis for the unique morphological and immunohistochemical features that differentiate them from their pre-existing counterparts.

If confirmed, our findings and hypothesis will provide, for the first time, a morphologically defined structure of newly formed vasculatures, a tube-like structure with co-expression of D2-40 and CD34, which may have significant scientific and clinical implications. Scientifically, as these structures appear to be exclusively associated with stem cells within both the epithelial and stromal components, identification of these structures may significantly benefit the study of stem cell biology. The isolation and identification of the unique molecules associated with these structures may lead to the development of more effective therapeutic agents to specifically target these structures. Clinically, as these tube-like structures with disseminated cells are exclusively or predominantly seen in 
node-positive cases, the presence or absence of these structures within the primary tumor may represent a reliable predictor for the metastatic potential of a given CRC. Thus, morphological and immunohistochemical assessment of the biopsy samples of a given CRC patient before the operation may substantially benefit the decision making process for both the surgical approach and the selection of treatment options. In addition, as aberrant lymphocyte infiltration appears to be a trigger for colorectal carcinogenesis and progression, systemic or localized administration of anti-inflammatory agents to the high risk population of CRC patients may have significant preventative value.

\section{Acknowledgments}

This study was supported in part by grants 200601060, 201108004 from Science and Technology Bureau of Nanjing, ZKX11004from Health Bureau of Nanjing, LZ11105 from Jiangsu Province Bureau of Traditional Chinese Medicine to Jiang Bin. This study was also supported in part by grants 2008-02 from the US Military Cancer Institute and Henry M. Jackson Foundation and 2006CB910505 from the Chinese Ministry of Science and Technology to Yan-gao Man and Xichen Zhang, by Merit Award ONCA-037-10F from the Veterans Health Administration awarded to Jeffrey Mason, and by RO1-DE12880 from NIDCR-NIH to Anahid Jewett.

\section{Competing Interests}

The authors have declared that no competing interest exists.

\section{References}

1. Karsa LV, Lignini TA, Patnick J, Lambert R, Sauvaget C. The dimensions of the CRC problem. Best Pract Res Clin Gastroenterol. 2010; 24(4):381-96

2. Zhou MG, Wang XF, Hu JP, et al. Geographical distribution of cancer mortality in China, 2004-2005. Zhonghua Yu Fang Yi Xue Za Zhi. 2010; 44(4):303-8.

3. Lei T, Chen WQ, Zhang SW, et al. Prevalence trend of colorectal cancer in 10 cities and counties in China from 1988 to 2002. Zhonghua Zhong Liu Za Zhi. 2009; 31(6):428-33.

4. Michor F, Iwasa Y, Rajagopalan H, Lengauer C, Nowak MA. Linear model of colon cancer initiation. Cell Cycle. 2004; 3(3):358-62.

5. Aaltonen LA. The multistep process of colon carcinogenesis. Cytokines Mol Ther. 1996; 2(2): 111-14.

6. Luebeck EG, Moolgavkar SH. Multistage carcinogenesis and the incidence of colorectal cancer. Proc Natl Acad Sci USA. 2002; 99(23):15095-100.

7. Barugel ME, Vargas C, Krygier Waltier G. Metastatic colorectal cancer: recent advances in its clinical management. Expert Rev Anticancer Ther. 2009; 9(12):1829-47.

8. Chen SL, Steele SR, Eberhardt J, et al. Lymph node ratio as a quality and prognostic indicator in stage III colon cancer. Ann Surg. 2011; 253(1):82-7.

9. Labianca R, Merelli B. Screening and diagnosis for colorectal cancer: present and future. Tumori. 2010; 96(6):889-901.

10. Robertson JH, Sarkar S, Yang SY, Seifalian AM, Winslet MC. In vivo models for early development of colorectal liver metastasis. Int J Exp Pathol. 2008; 89(1):1-12
11. Gutman M, Fidler IJ. Biology of human colon cancer metastasis. World J Surg. 1995;19(2):226-34.

12. Banerjee A, Quirke P. Experimental models of colorectal cancer. Dis Colon Rectum. 1998; 41(4): 490-505.

13. Christoph Wissmann and Michael Detmar. Pathways Targeting Tumor Lymphangiogenesis. Clin Cancer Res. 2006; 12(23):6865-8.

14. Cueni LN, Detmar M. New insights into the molecular control of the lymphatic vascular system and its role in disease. J Invest Dermatol. 2006;126:2167-77.

15. Nagy JA, Vasile E, Feng D, et al. Vascular permeability factor/vascular endothelial growth factor induces lymphangiogenesis as well as angiogenesis. J Exp Med. 2002; 196:1497-506.

16. Hong YK, Lange-Asschenfeldt B, Velasco P, et al. VEGF-A promotes tissue repair-associated lymphatic vessel formation via VEGFR-2 and the a1 $\beta 1$ and $\alpha 2 \beta 1$ integrins. FASEB J. 2004; 18:1111-3.

17. Kunstfeld R, Hirakawa S, Hong YK, et al. Induction of cutaneous delayed-type hypersensitivity reactions in VEGF-A transgenic mice results in chronic skin inflammation associated with persistent lymphatic hyperplasia. Blood. 2004; 104:1048-57

18. Morisada T, Oike Y, Yamada Y, et al. Angiopoietin-1 promotes LYVE-1-positive lymphatic vessel formation. Blood. 2005; 105:4649-56.

19. Tammela T, Saaristo A, Lohela M, et al. Angiopoietin-1 promotes lymphatic sprouting and hyperplasia. Blood. 2005; 105:4642-8.

20. Kajiya K, Hirakawa S, Ma B, Drinnenberg I, Detmar M. Hepatocyte growth factor promotes lymphatic vessel formation and function. EMBO J. 2005; 24:2885-95.

21. Kubo H, Cao R, Brakenhielm E, Makinen T, Cao Y, Alitalo K. Blockade of vascular endothelial growth factor receptor-3 signaling inhibits fibroblast growth factor-2-induced lymphangiogenesis in mouse cornea. Proc Natl Acad Sci USA. 2002; 99:8868-73.

22. Chang LK, Garcia-Cardena G, Farnebo F, et al. Dose-dependent response of FGF-2 for lymphangiogenesis. Proc Natl Acad Sci USA. 2004; 101:11658-63.

23. Cao R, Bjorndahl MA, Religa $P$, et al. PDGF-BB induces intratumoral lymphangiogenesis and promotes lymphatic metastasis. Cancer Cell. 2004; 6:333-45.

24. Bjorndahl M, Cao R, Nissen LJ, et al. Insulin-like growth factors 1 and 2 induce lymphangiogenesis in vivo. Proc Natl Acad Sci USA. 2005; 102:15593-8.

25. Mumprecht V, Roudnicky F, Detmar M. Inflammation-induced lymph node lymphangiogenesis is reversible. Am J Pathol. 2012; 180(3):874-9.

26. Huggenberger R, Siddiqui SS, Brander D, et al. An important role of lymphatic vessels activation limiting acute inflammation. Blood. 2011; 117(17):4667-78.

27. Cueni LN, Hegyi I, Shin JW, et al. Tumor lymphangiogenesis and metastasis to lymph nodes induced by cancer cell expression of podoplanin. Am J Pathol. 2010; 177(2):1004-16

28. Hirakawa S, Brown LF, Kodama S, Paavonen K, Alitalo K, Detmar M. VEGF-C-induced lymphangiogenesis in sentinel lymph nodes promotes tumor metastasis to distant sites. Blood. 2007; 109(3):1010-7.

29. Bos FL, Caunt M, Peterson-Maduro J, et al. Schulte-Merker SCCBE1 is essential for mammalian lymphatic vascular development and enhances the lymphangiogenic effect of vascular endothelial growth factor-C in vivo. Circ Res. 2011; 109(5):486-91.

30. Böhmer R, Neuhaus B, Bühren $S$, et al. Regulation of developmental lymphangiogenesis by Syk(+) leukocytes. Dev Cell. 2010; 18(3):437-49.

31. Ji RC. Macrophages are important mediators of either tumor- or inflammation-induced lymphangiogenesis. Cell Mol Life Sci. 2012; 69(6):897-914

32. Norrmén C, Vandevelde $\mathrm{W}, \mathrm{Ny}$ A, et al. Liprin (beta) 1 is highly expressed in lymphatic vasculature and is important for lymphatic vessel integrity. Blood. 2010; 115(4): 906-9.

33. Paupert J, Sounni NE, Noël A. Lymphangiogenesis in post-natal tissue remodeling: lymphatic endothelial cell connection with its environment. Mol Aspects Med. 2011; 32(2):146-58.

34. Shojaei F. Anti-angiogenesis therapy in cancer: current challenges and future perspectives. Cancer Lett. 2012; 320(2):130-7.

35. Lu R, Kujawski M, Pan H, Shively JE. Tumor angiogenesis mediated by myeloid cells is negatively regulated by CEACAM1. Cancer Res. 2012; 72(9):2239-50.

36. Bagnasco L, Piras D, Parodi S, et al. Role of angiogenesis inhibitors in colorectal cancer: sensitive and insensitive tumors. Curr Cancer Drug Targets. 2012; 12(4):303-15.

37. Lee YJ, Lee HJ, Choi SH, et al. Soluble HSPB1 regulates VEGF-mediated angiogenesis through their direct interaction. Angiogenesis. 2012; 15(2):229-42. 
38. Man YG, Tai L, Barner R, et al. Cell clusters overlying focally disrupted mammary myoepithelial cell layers and adjacent cells within the same duct display different immunohistochemical and genetic features: implications for tumor progression and invasion. Breast Cancer Res. 2003; 5: R231-41.

39. Man YG, Sang QXA. The significance of focal myoepitehlial cell layer disruptions in breast tumor invasion: a paradigm shift from the "protease-centered" hypothesis. Exp Cell Res. 2004; 301:103-18.

40. Man YG, Zhang $Y$, Shen $T$, et al. cDNA expression profiling identifies elevated expressions of tumor progression and invasion related genes in cell clusters of in situ breast tumors. Breast Cancer Res Treat. 2005; 89:199-208.

41. Man YG. Focal degeneration of aged or injured myoepithelial cells and the resultant auto-immunoreactions are trigger factors for breast tumor invasion. Med Hypoth. 2007; 69(6): 1340-57.

42. Man YG, Gardner WA. Focal degeneration of basal cells and the resultant auto-immunoreactions: a novel mechanism for prostate tumor progression and invasion. Med Hypoth. 2008; 70:387-408.

43. Man YG. Tumor cell budding from focally disrupted tumor capsules: a common pathway for all breast cancer subtype derived invasion? J Cancer. 2010, 1: 27-31.

44. Man YG. A seemingly most effective target for early detection and intervention of prostate tumor Invasion. J Cancer. 2010; 1: 63-9.

45. Hsiao YH, Su YA, Tsai HD, et al. Increased invasiveness and aggressiveness in breast epithelia with cytoplasmic p63 expression. Int J Biol Sci. 2012; 6(5): 428-42.

46. Man YG, Fu S, Liu AJ, et al. Aberrant expression of chromogranin A, mir-146a, and mir-146b-5p in prostate structures with focally disrupted basal cell layers: an early sign of invasion and hormone-refractory cancer? Cancer Genom \& Proteom. 2011; 8(5): 235-44.

47. Man YG, Harley R, Mason J, Gardner WA. Contributions of leukocytes to tumor invasion and metastasis: the "piggy-back" hypothesis. Cancer Epidemiol. 2010; 34(1): 3-6.

48. Hsiao YH, Deng CX, Mason JT, et al. Hidden malignant cells within leukocyte aggregates in normal or hyperplastic tissues of pregnancy-associated breast cancer. Cancer Epidemiol. 2011; 35(5):475-9.

49. Man YG, Mason J, Harley R, et al. Leukocyte-facilitated tumor dissemination: findings from multiple types of human tumors. J Cell Biochem. 2011; 112(4):1154-67.

50. Song G, Ren J, Stojadinovic A, et al. Conjunction of tumor cells with lymphocytes: Implications for tumor invasion and metastasis. Cancer Epidemiol. 2012; 36(4):354-63.

51. Puspa Raj Pandey PR, Saidou J, Watabe K. Role of myoepithelial cells in breast tumor progression. Front Biosci 2011,15: 226-36.

52. Noffsinger A, Fenoglio-Preiser CM, Maru D, Gilinsky N. Gastrointestinal Diseases. Washington DC: American Registry of Pathology and Armed Forces Institute of Pathology. 2007.

53. Nieroda CA, Arnold MW, Barbera-Guillem E, Martin EW. Lymphadenectomy in colorectal carcinoma. Chirurg. 1998; 69(7):717-24.

54. Fantini MC, Pallone F. Cytokines: from gut inflammation to colorectal cancer. Curr Drug Targets. 2008; 9(5):375-80.

55. Kraus S, Arber N. Inflammation and colorectal cancer. Curr Opin Pharmacol. 2009; 9(4):405-10.

56. Burstein E, Fearon ER. Colitis and cancer: a tale of inflammatory cells and their cytokines. J Clin Invest. 2008; 118(2):464-7.

57. Rizzo A, Pallone F, Monteleone G, Fantini MC. Intestinal inflammation and colorectal cancer: a double-edged sword? World J Gastroenterol. 2011; 17(26):3092-100.

58. Michel M, Török N, Godbout MJ, et al. Keratin 19 as a biochemical marker of skin stem cells in vivo and in vitro: keratin 19 expressing cells are differentially localized in function of anatomic sites, and their number varies with donor age and culture stage. J Cell Sci. 1996; 109 ( Pt 5):1017-28.

59. Larouche D, Hayward C, Cuffley K. Germain L.Keratin 19 as a stem cell marker in vivo and in vitro. Methods Mol Biol. 2005; 289:103-10.

60. Naujok O, Francini F, Jörns A, Lenzen S. An efficient experimental strategy for mouse embryonic stem cell differentiation and separation of a cytokeratin-19-positive population of insulin-producing cells. Cell Prolif. 2008; 41(4):607-24.

61. Larouche D, Lavoie A, Paquet C, Simard-Bisson C, Germain L. Identification of epithelial stem cells in vivo and in vitro using keratin 19 and BrdU. Methods Mol Biol. 2010; 585:383-400.

62. Lu CY, Uen YH, Tsai HL, et al. Molecular detection of persistent postoperative circulating tumour cells in stages II and III colon cancer patients via multiple blood sampling: prognostic significance of detection for early relapse. Br J Cancer. 2011; 104(7):1178-84.
63. Sun GR, Dong XY, He QS, et al. Expression and clinical significance of CK19 and CK20 expressions in transverse mesocolon biopsies from patients with gastric carcinoma. Cell Biochem Biophys. 2012; 62(2):361-4.

64. Kim H, Choi GH, Na DC, et al. Human hepatocellular carcinomas with "Stemness"-related marker expression: keratin 19 expression and a poor prognosis. Hepatology. 2011; 54(5):1707-17.

65. Rozhkova NI, Bozhenko VK, Ploshnitsa AI, et al. Cytokeratin 19 mRNA concentration in lymph nodes as a diagnostic marker of metastases. Bull Exp Biol Med. 2008; 145(1):90-2.

66. Suzuki A, Sekiya S, Gunshima E, et al. EGF signaling activates proliferation and blocks apoptosis of mouse and human intestinal stem/progenitor cells in long-term monolayer cell culture. Lab Invest. 2010; 90(10):1425-36.

67. Feng $\mathrm{Y}$, Dai $\mathrm{X}, \mathrm{Li} \mathrm{X}$, et al. EGF signalling pathway regulates colon cancer stem cell proliferation and apoptosis. Cell Prolif. 2012; 45(5):413-9.

68. Hicklin DJ, Ellis LM. Role of the vascular endothelial growth factor pathway in tumor growth and angiogenesis. J Clin Oncol. 2005; 23(5):1011-27.

69. Hogan NM, Dwyer RM, Joyce MR, Kerin MJ. Mesenchymal stem cells in the colorectal tumor microenvironment: recent progress and implications. Int J Cancer. 2012; 131(1):1-7. 